\title{
AS TECNOLOGIAS DIGITAIS NO DESENVOLVIMENTO DO RACIOCÍNIO LÓGICO
}

\author{
DIGITAL TECHNOLOGIES IN THE \\ DEVELOPMENT OF RATIONAL LOGIC \\ LES TECHNOLOGIES DIGITALES DANS LE \\ DEVELOPPEMENT DE LA PENSEE LOGIQUE \\ LAS TECNOLOGÍAS DIGITALES EN EL \\ DESARROLLO DEL RACIOCINIO LÓGICO
}

\author{
Hermínio Borges Neto * \\ Suzana Maria Capelo Borges **
}

\begin{abstract}
RESUMO
O trabalho analisa modos de utilização da informática educativa para o desenvolvimento do raciocinio lógico dos alunos, recorrendo às teorias de Piaget e à Seqüiência Fedathi, criada por nós e desenvolvida por um grupo de educadores do Laboratório de Pesquisa Multimeios da Faculdade de Educação da Universidade Federal do Ceará. Apresenta formas de usar os computadores, tipos de aplicativos e softwares, listando uma série de atitudes que se deve tomar ao interagir com essas máquinas, necessárias ao desenvolvimento da autonomia, da capacidade de criar e trabalhar com hipóteses. Por outro lado, destacam-se alguns cuidados que o professor, como mediador, deve ter com o uso dos computadores para que os alunos desenvolvam seu raciocinio lógico e sejam capazes de pensar e construir seu próprio conhecimento.
\end{abstract}

Palavras-chave: Tecnologias digitais. Informática educativa. Raciocinio lógico. Piaget. Seqüência Fedathi.

* Doutor em Matemática pela Associação Instituto Nacional de Matemática Pura e Aplicada (IMPA, 1979). Pós-Doutor pela Université de Paris VII (França, 1996). Professor da Faculdade de Educação da Universidade Federal do Ceará (UFC). Coordenador do Laboratório de Pesquisa Multimeios. Pesquisador do CNPq (herminio@multimeios.ufc.br).

** Doutora em Educação pela Universidade Federal do Ceará (UFC, 2005). Professora da Faculdade de Filosofia da Universidade Estadual do Ceará (UECE). Pesquisadora do Laboratório de Pesquisa Multimeios (suzana@multimeios.ufc.br). 
O progresso tecnológico das ultimas décadas e os avanços teóricos da psicologia passaram a demandar novas concepções de situações de aprendizagem e novos métodos pedagógicos de educação. A atividade do aluno passou a ter um papel central no desenvolvimento cognitivo e na formação de todo e qualquer conhecimento, cujas repercussóes incidem na maneira de se conceber o ensino e o papel do professor. Além disso, com a inclusão das novas tecnologias em ambientes escolares de ensino e aprendizagem, houve modificações substanciais em tais ambientes, o que exige conhecimento para a sua adequada utilização.

A preocupação com esse tema é fruto de nossa atividade didática e do fato de ainda verificarmos dificuldades dos professores (que formamos) em utilizar, de modo adequado e produtivo, as tecnologias digitais em seu dia-a-dia. Tentaremos desenvolver esse tema, baseados em duas teorias: a cognitivista de Piaget, amplamente difundida no mundo todo, gerando seguidores preocupados com a aplicação de suas teorias, como Seymour Papert (micromundo LOGO ou "geometria da tartaruga" - ambientes de exploração, descoberta e aprendizagem com a possibilidade de o aluno elaborar, modificar e melhorar seus próprios projetos, baseado na inteligência artificial e na teoria de Piaget) na computação e Louis Johannot (1947) no Ensino da Matemática, e a corrente conhecida como Seqüência Fedathi (BORGES NETO, 2001), criada por nós e desenvolvida por um grupo de educadores do Laboratório Multimeios da Faculdade de Educação da Universidade Federal do Ceará - UFC.

A primeira publicação deste grupo remonta a 1993 e encontra-se nos cadernos de Pós-Graduação da Faced - UFC, n. 1, v. 2. Não nos ateremos a discutir os prós e os contras de cada corrente como Yves de La Taille (1990) o fez em sua tese de doutorado sobre os trabalhos de Papert, mas tentaremos refletir sobre aquilo que consideramos adequado, segundo nossa visão e formação, sobre o que podemos obter de vantagens com o uso do computador, em relação ao desenvolvimento do raciocínio lógico. Esperamos também conseguir mobilizar os professores a organizar situaçôes de ensino que levem o aluno a pensar por si mesmo, a analisar e a questionar os conteúdos dados pela escola.

\section{UMA BREVE REVISÃO DA TEORIA DE PIAGET}

A teoria do desenvolvimento cognitivo de Jean Piaget ou do desenvolvimento lógico se compõe de quatro estágios, e cada um representa as transformações cognitivas por que passa a criança. Esses estágios ocorrem sob determinadas condiçóes: 1) a sucessão das condutas é constante, independente de aceleraçōes/atrasos que alterem a idade cronológica, em função das próprias experiências e estimulações do meio; 2) cada estágio é definido por uma estrutura de conjunto que define todas as novas condutas próprias dessa fase; 3 ) essas estruturas pressupõem grande integração, pois cada uma é preparada pela antecedente e incorporada à seguinte. Em suma, no terreno da inteligência cada estágio prepara o próximo, portanto, não há saltos evolutivos (RAMOZZI-CHIAROTTINO, 2005). 
Para Piaget (1978), o desenvolvimento mental envolverá ações que exigirão uma organização progressiva, como uma adaptação, cada vez mais precisa, à realidade, pois:

...o desenvolvimento orienta-se, essencialmente, para o equilíbrio [...] é portanto, uma equilibração progressiva, uma passagem contínua de um estado de menor equilíbrio para um estado de equilíbrio superior (p. 11).

[...] Toda ação - isto é, todo movimento, pensamento ou sentimento - corresponde a uma necessidade. A criança, como o adulto, só executa alguma ação exterior ou mesmo inteiramente interior quando impulsionado por um motivo e este se traduz sempre sob a forma de uma necessidade, que é sempre a manifestação de um desequilíbrio (p. 14).

No modelo piagetiano, o sistema cognitivo interage com o ambiente captando dados, que após serem processados assumem a forma de informações. Através de múltiplas interações, esse sistema passa por mudanças evolutivas que ampliam a capacidade de utilizar essas informaçôes para integrar-se, da melhor forma, ao mundo. As experiências ou ações do indivíduo com o meio propiciam a elaboração de representações mentais da realidade, que não são simples cópias do que é experimentado como real nessas interações.

Esses dois momentos são chamados por Piaget de assimilação e acomodação. A assimilação implica interpretação e construção de dados externos que devem ser incorporados aos conhecimentos preexistentes. A acomodação, por sua vez, modifica o sistema cognitivo para adequar-se ao que é percebido como dado externo.

Segundo Piaget (1978, p. 15),

...toda vida mental e orgânica tende a assimilar progressivamente o meio ambiente, realizando esta incorporação graças às estruturas ou órgãos psíquicos, cujo raio de ação se torna cada vez mais amplo [...]. Ora, assimilando assim os objetos, a ação e o pensamento são compelidos a se acomodarem a estes, isto é, se reajustarem por ocasião de cada variação exterior. Pode-se chamar "adaptação" ao equilíbrio destas assimilações e acomodações.

Esse intercâmbio ativo e simultâneo, de assimilação e acomodação a elementos externos ainda não-assimilados, provoca uma mudança na estrutura interna desse sistema, e é aí que ocorre o desenvolvimento cognitivo. Neste modelo, portanto, a mudança cognitiva do pensamento pode evoluir gradualmente com a maturação, a interação e a experiência.

Dos estágios de desenvolvimento cognitivo, que são o sensório-motor, o pré-operatório, o operatório e o formal, interessam-nos aqui apenas os dois últimos, quais sejam: o operatório-concreto e o operatório-formal. O operatório-concreto se caracteriza pela necessidade de, ao se apresentar uma situação a ser resolvida, um problema a ser solucionado, termos a situação instanciada e explícita, podendo ser manipulada concretamente. Em matemática, falamos de lógica proposicional, em que as idéias e os elementos verdadeiramente significativos são integrados e relacionados aos argumentos utilizados para a resolução da situação. Nesta lógica, os objetos precisam ser instanciados, mostrados, manipulados, daí o sentido do concreto, e, por isto, a representação mental não é tão flexível, pois ainda se baseia no objeto real. 
À medida que se desenvolve a presente lógica, o pensamento começa a se organizar em função de modelos que representam a situação dada sem haver necessidade de termos uma reprodução real da situação, "pois o conhecimento supera o próprio real para inserir-se no possível e ligar diretamente o possível ao necessário sem a mediação indispensável do conceito" (PIAGET, 2002, p. 48).

O pensamento formal é capaz de avaliar os dados do problema, ou de criar uma situação hipotética plausível sobre o problema, verificar ou testar sua teoria através de experimentos para ver o que realmente acontece e, só então, aceitar, rejeitar ou reformular sua hipótese, verificando se ela ocorre, logicamente ou não, na realidade. "Como as hipóteses são proposições, o aluno passa a trabalhar com operaçôes intraproposicionais de classes, relações etc" (PIAGET, 2002, p. 48).

Esse tipo de abstração interiorizada corresponde à abstração lógica e matemática, que é reflexiva, pois se constituiu de uma reflexão interna, de uma reorganização, de uma projeção que se depreendeu das ações para um plano mais elevado, mais complexo e superior de pensamento.

A noção de metacognição implica estar consciente dos próprios processos cognitivos, isto é, saber como é o seu raciocínio e quais podem ser as suas estratégias de pensamento. Envolve também saber que sabe, avaliar o que faz, ter conhecimento acerca do próprio conhecimento, o que permite monitorar ativamente a eficácia das estratégias cognitivas que é capaz de empregar para a resolução de uma dada situação.

Para Flavell, Miller e Miller (1999, p. 130):

A capacidade de um indivíduo empregar e reempregar suas forças cognitivas inteligentemente ao longo do tempo de acordo com as necessidades e as circunstâncias que mudam parece ser essencial para uma adaptação bem sucedida às situaçôes de vida complexas e instáveis que a maioria de nós enfrenta - na escola e fora dela.

O pensamento formal é, portanto, de natureza metacognitiva, pois envolve o pensar sobre os próprios processos de pensamento, isto é, pensar sobre hipóteses, proposições e possibilidades, muitas vezes imaginadas, que podem ou não ser fundamentadas em representações do real.

O modelo construído (STANAT; MCALLISTER, 1977) se encarregará disso, e a possibilidade de se trabalhar com essa forma de representar uma realidade permite: a) generalizar situaçôes, ou seja, de uma determinada situação partir-se para outra bem diferente; b) fazer simulaçôes e ensaios; c) levantar hipóteses a priori. Na lógica matemática, esse tipo de pensamento corresponde a uma lógica de primeira ordem (como assim denomina STANAT, 1977, p. 20), ou lógica dos quantificadores, como é denominada pelos matemáticos (DAVIS; HERSCH, 1986).

Daremos um exemplo de uma experiência que realizamos na Faculdade de Educação da UFC, em um curso de Didática da Matemática, que, esperamos, clarifique as noções 
sobre estes dois estágios e aquilo que estamos discutindo. Apresentou-se um problema para os alunos em que era colocado: dois trens em velocidade constante partiam das cidades A e B na mesma direção, com velocidades respectivas de 40 e $60 \mathrm{~km} / \mathrm{h}$, sendo a distância entre A e B de $30 \mathrm{~km}$. Após quanto tempo os dois carros se encontrariam?

Para essa situação-problema apareceram várias soluções, dentre elas: alguns alunos, concretamente, desenharam os trens, as cidades e conseguiram resolver o problema. Outros partiram para a utilização da álgebra, para as fórmulas, ou representaram graficamente o problema, sem a necessidade do desenho.

Em resumo, os primeiros, ou aqueles que resolveram a situação-problema representando a solução em forma de desenho, bem próxima do dado, estariam no estágio operatório concreto, enquanto que os últimos, os que usaram fórmulas ou abstraçôes, estariam no estágio formal. Estes, provavelmente, seriam capazes de generalizar o problema, usar a mesma situação em um contexto bem mais geral, enquanto que os outros talvez não. Queremos deixar claro, entretanto, que apenas com esse exemplo não poderíamos jamais classificar em qual estágio de desenvolvimento cognitivo estariam esses alunos.

\section{A SEQÜÊNCIA FEDATHI}

A Seqüência Fedathi se baseia no ensino por resolução de problemas explorado por George Polya, nos anos 70, e foi desenvolvida no Laboratório de Pesquisa Multimeios da Universidade Federal do Ceará, inicialmente para o ensino de matemática, mas atualmente é utilizada de forma mais abrangente, em outras áreas, como o ensino de ciências e o ensino assistido por computador. A maior diferença entre a nossa a proposta e a de Polya (1978) está no fato que esta é centrada no indivíduo, enquanto a Seqüência Fedathi é centrada na mediação que deve ocorrer entre o professor e alunos.

Ao ser apresentado um problema (aqui entendido como qualquer situação que é colocada e que precise de uma resposta, satisfatória ou não) a um indivíduo, dependendo de suas respostas, poderão ser categorizadas etapas que ele utiliza quando foi solicitado a resolver esse problema.

Inicialmente, quando uma situação é apresentada a um indivíduo, ele faz uma tomada de posição, ou seja, ele recorre a uma base de conhecimentos específicos que poderão ser mais eficazes para a resolução da referida situação. Em seguida, passa por um período de maturação, onde a situação é amadurecida, associada, organizada e comparada com outras já conhecidas, em busca de uma solução para o problema. Após o relaxamento de encontrar a solução, parte-se em busca da prova, que é uma solução mais otimizada, mais elaborada, mais sistematizada e sem redundâncias. Esta solução permite partir-se para generalizações, para elaboraçōes de modelos teóricos. Ao conjunto desses estágios chamamos Seqüência Fedathi.

No ensino tradicional e, principalmente, no ensino de matemática, os dois estágios intermediários são geralmente esquecidos ou pouco valorizados. Esse esquecimento dá 
origem a problemas na aprendizagem e o ensino se constitui simplesmente como um mero repassar de fórmulas, um ensino por meio de regras, repetiçôes ou receitas, em vez de um ensino que leve à compreensão e ao significado que o aluno deve ter daquilo que aprende e, assim, adquira autonomia para construir seu próprio conhecimento.

Essa concepção muda o papel do professor, que indiscutivelmente é fundamental, mas não é apenas o de transmitir conhecimento, mas de criar as condições para que o aluno seja desafiado e aprenda a pensar e agir. O professor também deverá ser capaz de fazer uma avaliação metacognitiva das produçôes dos alunos, verificando que estratégias de aprendizagem utilizaram. Deverá ainda fazer com que os alunos tomem consciência sobre seus processos de resolução de problemas e a que modalidades de pensamento recorreram durante a elaboração daquele conhecimento, para que possam transferir as mesmas estratégias de um dado conteúdo para outros.

Afinal, se é nos dois níveis intermediários (maturação e solução) que temos possibilidade de realizar ensaios e erros, de fazer e refazer o problema, de pensar em simulaçōes, de elaborar e levantar hipóteses, apresentando-o em uma linguagem mais próxima do nosso conhecimento, por que são tão pouco explorados pelos professores? Existem outras formas de trabalhá-los? Será possível atingir esses estágios com o uso das tecnologias digitais?

\section{ATITUDES A SEREM TOMADAS AO SE TRABALHAR COM UM COMPUTADOR}

O uso das novas tecnologias digitais abre novas e interessantes possibilidades de conhecimentos e aprendizagens, mas envolve também perigos e limitaçôes, dependendo de sua utilização. Quando se interage com um computador, há diversas atitudes que se pode tomar. Dentre elas, podemos citar:

1) Trabalhar com programação. Há programas de programação para todos os gostos e níveis: o LOGO, software de autoria, planilhas eletrônicas, até a máquina de Post, invento do russo V. Uspensky (1985), que é uma máquina programável, sem chips e memória, criada em tiras de papel, a partir da tese de doutorado do matemático Emile Post;

2) Software de ensaios e simulações. Alguns jogos, como o Carmen SanDiego, aplicativos do tipo Modellus (http://phoenix.sce.fct.unl.pt/sce/pessoas /vdt/), Cabri-Géomètre (http://www-cabri.imag.fr), programas do tipo CAD ou ainda o sítio da Estação Exploratorium (http://www.exploratorium.com);

3) Resolução de problemas. A resolução de problemas é colocada no sentido bem amplo, como proposto por Polya (1977), partindo da resolução de uma equação diferencial parcial, passando pela tradução de um texto e chegando à manipulação de figuras; 
4) Consultar bases de dados, utilizando o material disponível e uso de hipertextos ou hipermídias na rede Internet;

5) Máquinas de Ensinar;

6) Uso de sistemas enciclopédicos ou tutoriais eletrônicos;

7) Desenvolvimento de Projetos Educacionais Interdisciplinares. Essa é a modalidade mais em vigor nos colégios que trabalham com Informática Educativa, na concepção de Borges Neto (1999). A grande questão é saber se o aluno aprende computação, os temas propostos a serem desenvolvidos, ou ambos. Segundo nossa experiência com as escolas que visitamos, ou que são visitadas por nossos alunos, a aprendizagem maior é, essencialmente, de computação. A interdisciplinaridade é uma porta para o ensino de computação, até porque o professor especialista não participa, em regra geral, desse processo, ficando a maior responsabilidade do andamento das tarefas dos alunos com os responsáveis pelos laboratórios.

8) Tele-presença. Espécie de ensino a distância mediada por um professor, onde há um software sendo trabalhado por alunos, compartilhado e assistido pelo professor, a distância. Experiências deste tipo podem ser encontradas na página do projeto TeleAmbiente: desenvolvimento de ferramentas adaptativas e interativas aplicadas no ensino à distância, encontrada em <http://www.multimeios.ufc.br> e financiado pelo CNPq, Finep e Funcap.

Essa lista engloba apenas algumas das formas de trabalhar com os computadores, mas há inúmeras outras exploradas há longo tempo na literatura especializada. Colocamos apenas essas formas porque elas ajudarão a nos deter em alguns aspectos que consideramos muito pertinentes, e, assim, poderemos correlacioná-las às teorias de Piaget e à Seqüência Fedathi.

\section{A INFORMÁTICA E O DESENVOLVIMENTO DO RACIOCÍNIO LÓGICO}

Não entraremos na discussão de aspectos metodológicos ou se a forma de trabalhar com os computadores é adequada ou não. O que pretendemos fazer é, a partir da listagem de atitudes tomadas ao se trabalhar com um computador, refletirmos se há favorecimento ou não do desenvolvimento do pensamento lógico.

Algumas atividades com o uso da informática possibilitam desenvolver:

a) Raciocínio algoritmizado: Essa atividade é claramente encontrada nos tópicos 1, 2 e 4 descritos acima. Baseado nos estágios de Piaget, na medida em que se decompõe um raciocínio em etapas, pode-se passar a trabalhar com situações muito mais gerais e complexas. Ou seja, partir do concreto para o abstrato.

b) Previsões: Encontra-se fortemente no tópico 2. O ensaio das previsões possibilita inferir o que pode acontecer a uma situação se modificarmos certas hipóteses. Raciocinar 
sobre hipóteses-hipotéticas é uma atividade do operatório formal. O raciocínio formal se inicia com a possibilidade e, subseqüentemente, chega à realidade. A situação é examinada detalhadamente para verificação de toda e qualquer possibilidade de solução, e, só então, sistematicamente, é procurada a solução real da situaçãoproblema. Além disso, desenvolve a autonomia do aluno, pois ele pode levantar suas hipóteses, fazer inferências, tirar conclusōes. Atividades assim podem ser trabalhadas no Cabri-géomètre, no software Modellus ou mesmo no GeoMeios, disponível na Web em http://geomeios.multimeios.ufc.br.

c) Simulações (visualizações, análises de situações instanciadas): Esta é a aplicação, ao nosso ver, mais adequada das tecnologias digitais na educação. Através de simulação (tomando-se o sentido mais amplo), de representação de um problema no computador, de análises de situaçóes particulares e ligadas ao problema, pode-se criar um novo paradigma para a educação.

Vejamos um exemplo bem simples em matemática. Suponhamos que temos um software que permite desenhar triângulos e medir seus ângulos e somá-los. Ora, esses ângulos são objetos de triângulos construídos, de modo que, ao se deslocar os seus vértices, a nova soma é automaticamente calculada. Tradicionalmente, só se experimenta algumas vezes, não mais que três. No computador, entretanto, em poucos segundos, são possíveis milhares de tentativas. Qual a pista que esta experimentação nos dá?

Quando não se gosta de matemática, pode-se dissecar um olho ou um sapo em www.exploratorium.com.

Essas atividades desenvolvem a autonomia do aluno e o trabalho em cima de hipóteses, fazendo com que todo o conhecimento de que dispõe possa ser avaliado, remodelado, transformado e ampliado, em novas interpretações e mais complexas relações. Então, não são estas características as QUE MAIS SE DESTACAM no tipo de raciocínio próprio do operatório formal?

\section{CUIDADOS COM ESSA UTILIZAÇÃO}

As novas tecnologias na educação, em especial as digitais, não serão seguramente os únicos ou os melhores recursos para resolver problemas da educação. São apenas algumas das ferramentas didático-pedagógicas no ambiente escolar, que, se forem bem trabalhadas, poderão dar muitos frutos, mas, caso contrário, podem se tornar uma nova "matemática moderna" (KLINE, 1976).

Em relação ao desenvolvimento do raciocínio lógico, lembramos que certos softwares possibilitam o desenvolvimento de habilidades cognitivas que necessitam uma atenção especial por parte do professor para que possa identificá-las e utilizá-las adequadamente com seus alunos em sala de aula, as quais denominamos: 
Ao Acaso: Uma resposta dada ao acaso implica uma escolha intuitiva, pois a pessoa que responde não possui nenhum procedimento lógico a priori, nenhuma pista ou indício. É apenas um "chute".

Tentativa e Erro: Após testar alguns procedimentos aleatórios, a pessoa isola os que não levaram às respostas certas e tenta outros até acertar. Não levanta, necessariamente, hipóteses.

Ensaio e Erro: A pessoa tem uma hipótese, que testa para tentar a solução correta. Não é um procedimento aleatório, é algo pensado e submetido a teste, intencionalmente.

Dedução: Procedimento tentado só após uma inferência ou análise a priori de tentativas já adotadas em algumas outras situações ou mesmo nessa.

Não havendo por parte do educador uma mediação adequada, o estudante corre o risco de ficar limitado apenas aos dois primeiros itens em suas respostas (o que equivale às etapas 1 e 3 da Seqüência Fedathi), quando o desejável é que as atividades didáticopedagógicas propiciem estimulações para o desenvolvimento de respostas a situações colocadas nos planos do Ensaio e Erro e da Dedução.

Ou seja, como o software sempre dá uma resposta (output), e isto está mais presente em aplicativos do tipo tutorial ou com os browsers de navegação na Internet, o aluno estará desenvolvendo seu raciocínio ao procurar obter uma resposta e, a partir daí, refletir e decidir qual resposta será a mais adequada para a situação apresentada.

O desenvolvimento exagerado das duas primeiras habilidades (Ao Acaso e Tentativa e Erro) ocasiona um obstáculo epistemológico ao desenvolvimento do raciocínio por hipóteses, não binárias, no qual o próprio indivíduo deverá ser capaz de fazer suas inferências, tirar suas conclusões e conseguir justificá-las, não aceitando apenas a resposta da máquina.

Esperamos, enfim, que nossas reflexões possam contribuir para um uso mais adequado e diversificado da informática educativa na sala de aula, ao destacar formas de se trabalhar com os estudantes e com os computadores, de modo que se possa favorecer o desenvolvimento de seu raciocínio lógico e torná-los capazes de pensar, elaborar e resolver problemas, ou, ainda, dar-lhes uma outra interpretação, construindo novos conhecimentos.

\section{Referências}

BORGES NETO, Hermínio. Uma classificação sobre a utilização do computador pela escola. Educação em Debate, Fortaleza, ano 21, v. 1, n. 27, p. 135-138, 1999.

; SANTANA, José Rogério. A teoria de Fedathi e sua relação com o Intuicionismo e a lógica do desenvolvimento matemático no ensino. XV EPENN - Encontro de Pesquisa Educacional do Norte e Nordeste, 2001. São Luis/MA: UFMA, 2001.

et al. A Sequîencia de Fedathi como proposta metodológica no ensino-aprendizagem de Matemática e sua aplicação no ensino de retas paralelas. XV EPENN - Encontro de Pesquisa Educacional do Norte e Nordeste. São Luis/MA: UFMA, 2001. 
DAVIS, Philip; HERSH, Reuben. A experiência matemática. Rio de Janeiro: F. Alves, 1986.

FLAVELL, John H.; MILLER, Patrícia H.; MILLER, Scott A. Desenvolvimento cognitivo. Trad.: Cláudia Dornelles. 3. ed. Porto Alegre: Artmed, 1999.

JOHANNOT, Louis. Le raisonnement mathématique de l'adolescent. Colection Actualités Pédagogiques et Psychologiques. Paris: Delachaux et Niestlé, 1947.

KLINE, Morris. O fracasso da matemática moderna, São Paulo: Ibrasa, 1976.

PAPERT, Seymour. Logo: computadores e educação. Trad.: José Armando Valente do original americano Mindstorms: children, computers and powerful ideas, Basic Books, 1980). 3. ed. São Paulo: Brasiliense, 1988.

PIAGET, Jean. Biologia e conhecimento. Petrópolis: Vozes, 2000.

. Seis estudos de psicologia. Rio de Janeiro: Forense-Universitária, 1978.

; INHELDER, Bärbel. A psicologia da criança. Rio de Janeiro: Bertrand Brasil, 1990.

POLYA, George. A arte de resolver problemas: um novo aspecto do método matemático. Trad.: Lisboa de Araújo. Rio de Janeiro: Interciência, 1978.

RAMOZZI-CHIAROTTINO, Zelia. Os “estágios" do desenvolvimento da inteligência. Coleção Memória da Pedagogia n. 1: Jean Piaget. Rio de Janeiro: Ediouro; São Paulo: Segmento-Duetto, 2005.

STANAT, Donald F; MCALLISTER, David F. Discrete mathematics in computer science. New Jersey, EUA: Prentice Hall, 1977.

TAILLE, Yves de La. Ensaio sobre o lugar do computador na Educação. São Paulo: Iglu, 1990.

USPENSKY, V. A máquina de Post. Moscou (URSS): Mir, 1985. 


\section{Digital technologies in the development of rational logic}

\section{Abstract}

This text analyses the modes of utilizing educational informatics for the development of rational thinking of students, referring to the theories of Piaget and the Fedathi Sequence, created by us and developed by a group of educators at the laboratory of Multimidia research at the Faculty of Education of the Universidade Federal do Ceará. It presents forms of using computers, types of applications and softwares, listing a series of attitudes which need to be taken in interacting with theses machines, and necessary for the development of autonomy, as well as the capacity of creating and working with hypotheses. On the other hand, a few precautions are pointed out which the teacher, as mediator, must take when using computers so that his students develop their logical thinking and be capable of thinking and building their own knowledge.

Keywords: Digital technologies. Educational informatics. Logical thinking. Piaget. Fedathi sequence.

\section{Les technologies digitales dans le développement de la pensée logique}

\section{Résumé}

Ce travail analyse différentes formes d'utilisation de l'informatique éducative pour le développement de la pensée logique des élèves en faisant référence aux théories de Piaget et de la Séquence Fedathi, créée et développée par un groupe d'éducateurs au sein du Laboratoire de Recherche Multimidia situé à la Faculté d'Éducation de l'Universidade Federal do Ceará. Il présente des façons d'utiliser les ordinateurs et logiciels, en listant des attitudes qui doivent être prises pendant linteraction avec ces machines, nécessaires au développement de l'autonomie et de la capacité de créer et de travailler avec des hypothèses. Par ailleurs, nous mettons en évidence quelques précautions que le professeur, comme médiateur, doit prendre quand il utilise des ordinateurs de manière à ce que les étudiants développent leur raisonnement logique et soient capables de penser et de construire leur propre connaissance.

Mots clefs : Technologies numériques. Informatique éducative. Raisonnement logique. Piaget. Séquence Fedathi.

\section{Las tecnologías digitales en el desarrollo del raciocinio lógico}

\section{Resumen}

El trabajo analisa modos de utilización de la informática educativa para el desarrollo del raciocinio lógico de los alumnos, recorriendo a las teorías de Piaget y la secuencia Fedathi, creada por nosotros y desarrollada por un grupo de educadores del laboratorio de investigación multimedios de la facultad de educación de la Universidade Federal do Ceará. Presenta formas de usar computadoras, tipos de aplicativos y softwares, listando una série de actitudes que se debe tomar al interagir con esas máquinas, necesarias al desarrollo de la autonomía, de la capacidad de crear y trabajar con hipótesis. Por otro lado, se destacan algunos cuidados que el profesor, como mediador, debe tener con el uso de los computadores para que los alumnos desarrollen su raciocinio lógico y sean capaces de pensar y construir su propio conocimiento.

Palabras-clave: Tecnologias digitales. Informática educativa. Raciocinio lógico. Piaget. Secuencia Fedathi.

Recebida I ${ }^{\text {a }}$ versão em: | 2.01 .2007

Aceita $2^{\mathrm{a}}$ versão em: 23.07.2007 
